Discussion Paper No. 791

\title{
PUBLIC DEBT PLACES NO BURDEN ON FUTURE GENERATIONS UNDER DEMAND SHORTAGE
}

\author{
Takayuki Ogawa \\ and \\ Yoshiyasu Ono
}

September 2010

The Institute of Social and Economic Research Osaka University

6-1 Mihogaoka, Ibaraki, Osaka 567-0047, Japan 


\title{
Public Debt Places No Burden on Future Generations under Demand Shortage*
}

\author{
TAKAYUKI OGaWA $^{\dagger}$ AND YOShIYASU ONO O $^{\ddagger}$
}

\begin{abstract}
In a Diamond-type overlapping-generations setting public debt issuance places no burden on future generations including those who repay the debt if prices and wages are fixed and unemployment occurs in the periods in which public bonds are issued and repaid. Whether the collected fund is spent on government purchases or transfers to the present generation, public bond issuance stimulates aggregate demand and creates additional employment of future generations, which yields additional income that is large enough to cover their tax burden. This property is true whether the debt is repaid by children or grandchildren.
\end{abstract}

Keywords: Demand shortage, Overlapping generations, Public debt, Unemployment, Welfare effects

JEL Classification Numbers: E24, E62, H63

*The authors would like to thank Koichi Futagami, Shinsuke Ikeda, and seminar participants at Kobe University and Osaka University for their helpful comments and suggestions. Ogawa is financially supported by the Grant-in-Aid for Young Scientists (Start-up) 18830085, the Japan Society for the Promotion of Science (JSPS), and the Grant-in-Aid from the Zengin Foundation for Studies on Economics and Finance. Financial support to Ono's research by the GCOE programs, the Ministry of Education, Culture, Sports, Science and Technology is also acknowledged.

${ }^{\dagger}$ Faculty of Economics, Osaka University of Economics, 2-2-8 Osumi, Higashiyodogawa-ku, Osaka 533-8533, Japan. Tel: +81-6-6328-2431; Fax: +81-6-6327-2390; E-mail: tkogawa@osaka-ue.ac.jp.

${ }^{\ddagger}$ Institute of Social and Economic Research, Osaka University, 6-1 Mihogaoka, Ibaraki, Osaka 5670047, Japan. Tel: +81-6-6879-8578; Fax: +81-6-6878-2766; E-mail: ono@iser.osaka-u.ac.jp. 


\section{Introduction}

Public debt burden is a long-discussed issue in the literature. For example, Tobin (1980, p. 49) states:

Do government deficits absorb private saving? Does public debt diminish private demand for stocks of productive capital assets? Can the burden of current government expenditure be shifted to future generations? These are old questions. Today they are once more in the forefront of economic controversy. Few issues of economic theory and fact evoke such polar disagreement. The contesting views carry radically divergent implications for public fiscal and financial policy.

This issue has become more relevant especially after the financial crisis of 2008. Many countries face serious economic turndown and are forced to expand fiscal spending by issuing public bonds, which provokes serious worries about debt burdens on future generations. Particularly in Japan serious stagnation continues for twenty years and a huge amount of public debt has accumulated. We reconsider this issue in the presence of demand shortage and involuntary unemployment and show that there is no public debt burden on future generations.

Public debt is widely believed to place burdens on future generations in the literature. Using an overlapping-generations model with finitely-lived agents, for example, Diamond (1965) finds that internal debt reduces capital accumulation (if the saddle-point stability is valid) and deteriorates steady-state welfare (if the economy is dynamically efficient). Blanchard (1985) and Weil (1989) obtain similar results in alternative overlapping-generations models with infinitely-lived agents. ${ }^{1}$ They find that public debt makes future generations worse off on the dynamically efficient path since it creates persistent income transfers

\footnotetext{
${ }^{1}$ Blanchard (1985) assumes that each agent anytime faces a common and constant instantaneous probability of death and thus all generations have the same average rest of life. Weil (1989) does not take account of the death probability. However, since the role of finite lifetime is negligible in the present context, as Buiter (1988) discusses, these two analyses have basically the same implication.
} 
from future generations to current generations. ${ }^{2}$ In these models public debt burden is due to intergenerational redistribution. ${ }^{3}$ While they consider the case of full employment, we use an overlapping-generations model with involuntary unemployment since a government more likely issues public bonds under stagnation so as to finance extra fiscal spending and create new demand. In this setting we show that there is no public debt burden on future generations although the economy is dynamically efficient. ${ }^{4}$

There are not many studies that explore the implication of public debt in the presence of demand shortage and involuntary unemployment. Among those, Tobin (1980) suggests that a helicopter drop of government bonds raises demand for current consumption and reduces unemployment whereas Modigliani (1961) argues that government bonds place burdens on future generations even in the presence of unemployment. However, both of them use ad hoc models without rational agent behavior. Rankin (1986) uses a Diamondtype overlapping-generations model with nominal price rigidity and analyze public debt

\footnotetext{
${ }^{2}$ Lopez-Garcia (2008) obtains basically the same result as Diamond (1965) in a model with endogenous labor supply. By developing an endogenous growth model with overlapping generations and production externalities, Saint-Paul (1992) shows that public debt reduces the growth rate and the welfare of some future generations. The implication of Diamond (1965), Blanchard (1985), and Weil (1989) has been extensively investigated in various directions. See e.g., Drazen (1978) for human capital accumulation, Persson (1985) for an open economy, Lapan and Enders (1990) for endogenous fertility, and Sen (2002) for monopolistic competition in the commodity market.

${ }^{3}$ There are other sources that make Ricardian equivalence invalid. They are e.g. capital market imperfections and distortionary taxation. See Bernheim (1987) and Romer (2005, ch. 11) for the condition of Ricardian equivalence to be invalid.

${ }^{4}$ Since neither population growth nor physical capital depreciation is assumed, the equilibrium path is dynamically efficient in our model. With full employment public debt issuance makes future generations worse off on the dynamically efficient path, as mentioned above. On the dynamically inefficient path, however, public debt issuance may make future generations better off because it remedies capital overaccumulation (see Diamond 1965 and Tirole 1985). Chalk (2000) and Rankin and Roffia (2003) examine whether there is a path toward the dynamically inefficient steady state where the government rolls over the debt forever, implying that future generations are not worse off on that path. In an uncertain economy setting, Bohn (1995), Ball et al. (1998), and Blanchard and Weil (2001) distinguish the rate of return on public bonds from that on physical capital to find a positive probability of deficit sustainability on the dynamically efficient path.
} 
burden. He shows that in the presence of excess supply in the commodity and labor markets, viz. "Keynesian unemployment" in Malinvaud's (1977) terminology, a permanent increase in public debt raises steady-state output and welfare under some reasonable conditions, including saddle-point stability.

The model of this paper has a similar structure as that of Rankin (1986) but differs from it in the following two aspects. First, we take into account employment of not only the young but also the old. Second, while Rankin focuses on the steady state only, we analyze the effect of a temporary increase in bonds in the transitional state. This extension enables us to distinguish the following three policies: (i) public debt is redeemed only by taxing on the current young, (ii) additional taxes are levied on not only the current young but also the generations that are not yet born, and (iii) deficit-covering bonds are issued to redeem the current bonds. ${ }^{5}$ We show that in any of these three cases there is no debt burden on future generations. Even if the old are employed due to fiscal spending and the young are taxed, employment of the young eventually increases enough to cover the tax payment, yielding no public debt burden on the young.

When analyzing public debt burdens on future generations in the presence of unemployment, Ogawa (2005) employs a model á la Blanchard (1985) and Weil (1989). He shows that whether or not public debt issuance makes future generations worse off depends on the amount of outstanding bonds. In that model all generations, including the current generation, coexist even in the future and hence a government can anytime redistribute debt burdens through appropriate taxation. In the Diamond model, in contrast, such redistribution is infeasible because the current generation does not exist when imposing a tax. Such a difference in the demographic structure between the two types of models leads to a different conclusion. This paper finds that public debt issuance never makes future generations worse off in the Diamond model.

Steigum (2001), Kaas and von Thadden (2004), and Josten (2006) take account of real wage rigidity due to the bargaining power of trade unions. Among them, Steigum (2001) shows that debt burdens on future generations that arise from postponement of

\footnotetext{
${ }^{5}$ We explicitly introduce equities whereas Rankin (1986) assumes that firm revenues are always transferred to the old. This difference does not alter the main implication.
} 
the labor income tax is larger with union power than without it. Kass and von Thadden (2004) compares unemployment dynamics under balanced and unbalanced budgets. Josten (2006) uses an endogenous growth model with production externalities and finds that an increase in the debt-to-capital ratio forces the government to raise the labor income tax, which worsens unemployment and decreases economic growth. Whereas they consider structural unemployment, we treat involuntary unemployment due to demand shortage. Using a New Open Economy Macroeconomics model with short-run nominal price rigidity, Ganelli (2005) considers a permanent tax cut financed by debt issuance that is maintained even after nominal prices fully adjust. He concludes that it leads to current account deficits and decreases long-run consumption in the home country. We in contrast examine the effect of debt issuance only in the period where nominal prices are fixed and find that consumption of future generations does not decline.

The rest of the paper is organized as follows. Section 2 presents the basic structure of the model and formulates the dynamics. Section 3 discusses the main implication of public debt burdens in the presence of Keynesian unemployment. Section 4 extends the analysis to the case of deficit-covering bond issuance. Section 5 concludes the paper.

\section{The Model}

Individuals live for two periods and two generations coexist at any point in time. The population size of each generation is normalized to unity. Nominal price $P_{t}$ and nominal wage $W_{t}$ are fixed and Keynesian unemployment occurs at least in the period in which bonds are issued and the period in which they are repaid. Note that the following argument holds whether prices and wages are rigid or flexible in the subsequent periods. ${ }^{6}$

Utility of an individual born in period $t$ depends on consumption when young and old,

\footnotetext{
${ }^{6}$ Rankin (1986) assumes nominal prices and wages to be fixed in all periods since he treats the effect of bond issuance in steady state. In contrast, we analyze the effect on economic variables in the period in which the bonds are issued and the period in which bonds are repaid in the presence of unemployment. Hence price/wage rigidities are required only in the relevant periods. See Ono (2001) for a recent discussion about public debt burdens under a liquidity trap and price/wage sluggishness.
} 
$c_{t}^{y}$ and $c_{t+1}^{o}$ respectively, and real money holdings $m_{t}\left(=M_{t} / P_{t}\right)$ at the end of her youth -i.e.,

$$
U_{t}=u\left(c_{t}^{y}\right)+v\left(m_{t}\right)+\theta u\left(c_{t+1}^{o}\right),
$$

where $u^{\prime}>0, u^{\prime \prime}<0, v^{\prime}>0, v^{\prime \prime}<0, \theta>0$.

Given real wage $w_{t}$ (or $w_{t+1}$ ), each individual earns wage income $w_{t} l_{t}^{y}$ (or $w_{t+1} l_{t+1}^{o}$ ) by supplying labor $l_{t}^{y}$ (or $l_{t+1}^{o}$ ) and pays lump-sum tax-cum-subsidy $z_{t}^{y}\left(\right.$ or $z_{t+1}^{o}$ ) when young (or old). She accumulates three kinds of interest-bearing assets, viz. public bond $b_{t+1}$, physical capital $k_{t+1}$, and equity $\nu_{t+1}$, when young, and receives returns $\left(1+r_{t+1}\right)\left(b_{t+1}+\right.$ $\left.k_{t+1}+\nu_{t+1}\right)$ when old, where $r_{t+1}$ is the real interest rate. The budget equations when young and old are respectively

$$
\begin{aligned}
& c_{t}^{y}+m_{t}+\left(b_{t+1}+k_{t+1}+\nu_{t+1}\right)=w_{t} l_{t}^{y}-z_{t}^{y}, \\
& c_{t+1}^{o}=\frac{1}{1+\pi_{t+1}} m_{t}+\left(1+r_{t+1}\right)\left(b_{t+1}+k_{t+1}+\nu_{t+1}\right)+w_{t+1} l_{t+1}^{o}-z_{t+1}^{o},
\end{aligned}
$$

where $\pi_{t+1}$ represents the inflation rate. These two equations reduce to the lifetime budget equation:

$$
c_{t}^{y}+\frac{R_{t+1}}{1+R_{t+1}} m_{t}+\frac{1}{1+r_{t+1}} c_{t+1}^{o}=\Omega_{t},
$$

where $R_{t+1}$ and $\Omega_{t}$ are respectively the nominal interest rate and the capitalized value of lifetime disposable income:

$$
\begin{aligned}
R_{t+1} & \equiv\left(1+r_{t+1}\right)\left(1+\pi_{t+1}\right)-1, \\
\Omega_{t} & \equiv w_{t} l_{t}^{y}-z_{t}^{y}+\frac{1}{1+r_{t+1}}\left(w_{t+1} l_{t+1}^{o}-z_{t+1}^{o}\right) .
\end{aligned}
$$

The individual chooses $\left(c_{t}^{y}, m_{t}, c_{t+1}^{o}\right)$ to maximize (1) subject to (4) and hence the optimal conditions are

$$
\begin{aligned}
u^{\prime}\left(c_{t}^{y}\right) & =\left(1+r_{t+1}\right) \theta u^{\prime}\left(c_{t+1}^{o}\right), \\
\frac{v^{\prime}\left(m_{t}\right)}{u^{\prime}\left(c_{t}^{y}\right)} & =\frac{R_{t+1}}{1+R_{t+1}} .
\end{aligned}
$$


Equations (4), (7) and (8) yield the following demand functions:

$$
\begin{aligned}
c_{t}^{y} & =c^{y}\left(\Omega_{t}, r_{t+1}, R_{t+1}\right), \\
m_{t} & =m\left(\Omega_{t}, r_{t+1}, R_{t+1}\right), \\
c_{t+1}^{o} & =c^{o}\left(\Omega_{t}, r_{t+1}, R_{t+1}\right),
\end{aligned}
$$

where $0<c_{\Omega}^{y}<1, m_{\Omega}>0, m_{R}<0$.

See Appendix A for the abovementioned properties of the demand functions.

The firm sector has the following production function:

$$
y_{t}=F\left(k_{t}, l_{t}\right), \quad \text { satisfying } F_{k}>0, F_{k k}<0, F_{l}>0, F_{l l}<0, F_{k l} \geq 0,
$$

where $k_{t}$ and $l_{t}$ are inputs of capital and labor respectively. Physical capital depreciation is assumed away, for simplicity. Since $P_{t}$ and $W_{t}$ are fixed in the relevant periods, which leads to shortages of commodity demand and labor demand, the firm sector minimizes the total cost of producing output $y_{t}$ and then

$$
\frac{F_{k}\left(k_{t}, l_{t}\right)}{r_{t}}=\frac{F_{l}\left(k_{t}, l_{t}\right)}{w_{t}}>1
$$

This equation gives $k_{t}$ as a function of $l_{t}, r_{t}$ and $w_{t}$ :

$$
k_{t}=k\left(l_{t}, r_{t}, w_{t}\right), \quad \text { where } k_{l}>0, k_{r}<0, k_{w}>0 \text {. }
$$

Because of the shortage of commodity demand the firm increases neither $k_{t}$ nor $l_{t}$ although the marginal productivity of each input exceeds each price, and hence the firm value $\nu_{t}$ is strictly positive. Since $k$ is given by (13), the dynamics of $\nu$ is

$$
\nu_{t+1}=\left(1+r_{t}\right) \nu_{t}-F\left(k\left(l_{t}, r_{t}, w_{t}\right), l_{t}\right)+r_{t} k\left(l_{t}, r_{t}, w_{t}\right)+w_{t} l_{t} .
$$

In the presence of labor demand shortage we have to assume a rule of job allocation between the young $\left(l_{t}^{y}\right)$ and the old $\left(l_{t}^{o}\right)$. It is

$$
l_{t}^{y}=l^{y}\left(l_{t}\right), \quad l_{t}^{o}=l_{t}-l^{y}\left(l_{t}\right), \quad \text { where } 0<l_{l}^{y} \leq 1 .
$$

Substituting (5), (9), (13) and (15) into (2) leads to

$$
\begin{aligned}
w_{t} l^{y}\left(l_{t}\right)-z_{t}^{y}= & c^{y}\left(\Omega_{t}, r_{t+1},\left(1+r_{t+1}\right)\left(1+\pi_{t+1}\right)-1\right) \\
& +m_{t}+b_{t+1}+k\left(l_{t+1}, r_{t+1}, w_{t+1}\right)+\nu_{t+1} .
\end{aligned}
$$


From (5), (6), (10), and (15) we find $r_{t+1}$ and $\Omega_{t}$ to satisfy

$$
\begin{aligned}
& m_{t}=m\left(\Omega_{t}, r_{t+1},\left(1+r_{t+1}\right)\left(1+\pi_{t+1}\right)-1\right) \\
& \Omega_{t}=w_{t} l^{y}\left(l_{t}\right)-z_{t}^{y}+\frac{1}{1+r_{t+1}}\left\{w_{t+1}\left[l_{t+1}-l^{y}\left(l_{t+1}\right)\right]-z_{t+1}^{o}\right\} .
\end{aligned}
$$

These two equations solve $r_{t+1}$ and $\Omega_{t}$ as functions of $l_{t}$ and $l_{t+1}$ for given price parameters $P_{s}$ and $W_{s}$ for $s=t, t+1$, and policy parameters $M_{t}, z_{t}^{y}$ and $z_{t+1}^{o}$. Applying them into (16) gives $l_{t+1}$ as a function of $l_{t}$ and $\nu_{t+1}$. Shifting (14) by one period and applying $r_{t+1}$ obtained from (17) into the result gives $\nu_{t+2}$ as a function of $l_{t}, \nu_{t+1}$ and $l_{t+1}$, where $l_{t+1}$ has already been given as a function of $l_{t}$ and $\nu_{t+1}$. Therefore, $l_{t+1}$ and $\nu_{t+2}$ are represented as functions of $l_{t}$ and $\nu_{t+1}-$ i.e., $l$ and $\nu$ formulate an autonomous dynamics. Note that we consider the case where nominal prices and wages are fixed and so are $\left(w_{t}, w_{t+1}, \pi_{t+1}, m_{t}\right)$ in the relevant periods.

Totally differentiating the dynamics of $l$ and $\nu$ gives effects of bond issuance $b_{t+1}$ and tax burdens $z_{t}^{y}$ and $z_{t+1}^{o}$ on the dynamic paths of $l$ and $\nu$ :

$$
A_{t}\left(\begin{array}{c}
\mathrm{d} l_{t+1} \\
\mathrm{~d} \nu_{t+2}
\end{array}\right)=B_{t}\left(\begin{array}{c}
\mathrm{d} l_{t} \\
\mathrm{~d} \nu_{t+1}
\end{array}\right)+C_{t}\left(\begin{array}{c}
\mathrm{d} b_{t+1} \\
\mathrm{~d} z_{t}^{y} \\
\mathrm{~d} z_{t+1}^{o}
\end{array}\right)
$$

where

$$
\begin{aligned}
A_{t} & \equiv\left(\begin{array}{cc}
\frac{\alpha_{t} \zeta_{t}-\beta_{t} \epsilon_{t}}{\zeta_{t}} & -\frac{\beta_{t}}{\zeta_{t}} \\
\frac{\gamma_{t} \zeta_{t}-\delta_{t} \epsilon_{t}}{\zeta_{t}} & -\frac{\delta_{t}}{\zeta_{t}}
\end{array}\right), \\
B_{t} & \equiv\left(\begin{array}{cc}
-\left(1-c_{\Omega_{t}}^{y}\right) w_{t} l_{l_{t}}^{y} & \frac{\zeta_{t}-\left(1+r_{t+1}\right) \beta_{t}}{\zeta_{t}} \\
m_{\Omega_{t}} w_{t} l_{l_{t}}^{y} & -\frac{\left(1+r_{t+1}\right) \delta_{t}}{\zeta_{t}}
\end{array}\right), \\
C_{t} & \equiv\left(\begin{array}{ccc}
1 & 1-c_{\Omega_{t}}^{y} & -\frac{c_{\Omega_{t}}^{y}}{1+r_{t+1}} \\
0 & -m_{\Omega_{t}} & -\frac{m_{\Omega_{t}}}{1+r_{t+1}}
\end{array}\right) .
\end{aligned}
$$




$$
\begin{aligned}
\alpha_{t} & \equiv-\frac{c_{\Omega_{t}}^{y} w_{t+1}\left(1-l_{l_{t+1}}^{y}\right)}{1+r_{t+1}}-k_{l_{t+1}}(<0), \\
\beta_{t} & \equiv-\frac{c_{\Omega_{t}}^{y}\left(w_{t+1} l_{t+1}^{o}-z_{t+1}^{o}\right)}{\left(1+r_{t+1}\right)^{2}}+c_{r_{t+1}}^{y}+\left(1+\pi_{t+1}\right) c_{R_{t+1}}^{y}+k_{r_{t+1}}, \\
\gamma_{t} & \equiv-\frac{m_{\Omega_{t}} w_{t+1}\left(1-l_{l_{t+1}}^{y}\right)}{1+r_{t+1}}(<0), \\
\delta_{t} & \equiv-\frac{m_{\Omega_{t}}\left(w_{t+1} l_{t+1}^{o}-z_{t+1}^{o}\right)}{\left(1+r_{t+1}\right)^{2}}+m_{r_{t+1}}+\left(1+\pi_{t+1}\right) m_{R_{t+1}}, \\
\epsilon_{t} & \equiv\left(F_{k_{t+1}}-r_{t+1}\right) k_{l_{t+1}}+F_{l_{t+1}}-w_{t+1}(>0), \\
\zeta_{t} & \equiv \nu_{t+1}+k_{t+1}-\left(F_{k_{t+1}}-r_{t+1}\right) k_{r_{t+1}}(>0) .
\end{aligned}
$$

\section{$3 \quad$ No Burden on Future Generations}

Given that initially there is no public debt, this section considers the case where the government issues bonds to finance fiscal spending in period $T$ and repays them by taxing on the old and/or the young in period $T+1$ so that the original path is recovered in period $T+2$ and after. Section 4 treats the case where a tax is imposed also on the generation born in period $T+2$ but not on the generations born afterwards.

The government unanticipatedly issues bonds $\mathrm{d} b_{T+1}(>0)$ in period $T$ in order to finance government purchases $\mathrm{d} g_{T}(\geq 0)$ and subsidy $-\mathrm{d} z_{T}^{o}(\geq 0)$ to the old, and in period $T+1$ taxes $\mathrm{d} z_{T+1}^{o}(\geq 0)$ on the old and $\mathrm{d} z_{T+1}^{y}(\geq 0)$ on the young so as to redeem the bonds. That is,

$$
\begin{aligned}
\left\{\mathrm{d} b_{t}\right\}_{t=0}^{\infty} & =\left(0, \ldots, 0, \mathrm{~d} b_{T+1}, 0, \ldots, 0\right), \\
\mathrm{d} b_{T+1} & =\mathrm{d} g_{T}-\mathrm{d} z_{T}^{o}, \\
\mathrm{~d} z_{T+1}^{y}+\mathrm{d} z_{T+1}^{o} & =\left(1+r_{T+1}\right) \mathrm{d} b_{T+1} .
\end{aligned}
$$

Furthermore, in order to focus on the pure effect of bond issuance on the generations born in periods $T$ and $T+1$, we consider the bond issuance and the subsequent taxation that do not affect the utility levels of the generations born in period $t \in[T+2, \infty]$. Formally, in period $T+1$ the tax-cum-subsidy on the young $\mathrm{d} z_{T+1}^{y}$ is adjusted lest the dynamic path should change from the original one in the subsequent periods $t \in[T+2, \infty]$. Therefore, we substitute $\mathrm{d} l_{T+2}=0$ and $\mathrm{d} \nu_{T+3}=0$ into the dynamics (18) for $t=T+1$ 
and thereby find such $\mathrm{d} z_{T+1}^{y}$ to satisfy

$$
\left(\begin{array}{c}
-\left(1-c_{\Omega_{T+1}}^{y}\right) \\
m_{\Omega_{T+1}}
\end{array}\right) \mathrm{d} z_{T+1}^{y}=B_{T+1}\left(\begin{array}{c}
\mathrm{d} l_{T+1} \\
\mathrm{~d} \nu_{T+2}
\end{array}\right)
$$

which reduces to

$$
\mathrm{d} z_{T+1}^{y}=w_{T+1} l_{l_{T+1}}^{y} \mathrm{~d} l_{T+1}, \quad \mathrm{~d} \nu_{T+2}=0 .
$$

The implication is straightforward. If in period $T+1$ the government levies a $100 \%$ tax on the additional labor income of the young that is created by fiscal expansion (i.e., $\left.\mathrm{d} z_{T+1}^{y}=w_{T+1} l_{l_{T+1}}^{y} \mathrm{~d} l_{T+1}\right)$, the budget of the young is unaffected. Thus, in the subsequent periods employment and the firm value remain unchanged (i.e., $\mathrm{d} l_{t}=0$ and $\mathrm{d} \nu_{t+1}=0$ for $t \in[T+2, \infty])$.

\subsection{No Burden on Children}

Public debt is widely believed to place a burden on children by generating an income transfer from them to their parents. Theoretical studies, such as Diamond (1965), Blanchard (1985) and Weil (1989), support this view in the case of full employment. We in contrast treat the case of Keynesian unemployment and find that such burdens do not arise.

Because (19)-(22) imply no welfare effect on the generations born in period $t \in[T+$ $2, \infty]$, we can obtain the pure welfare effect on the children (viz., the generation born in period $T$ ) of bond issuance by assuming the following policy:

Policy 1. Public debt is fully redeemed by taxing on the old in period $T+1,-i . e ., d z_{T+1}^{o}=$ $\left(1+r_{T+1}\right) d b_{T+1}(>0)$ and $d z_{T+1}^{y}=0$.

Under (19)-(22) and Policy 1 a unique consistent equilibrium obtains as follows:

$$
\left(\begin{array}{c}
\mathrm{d} l_{T} \\
\mathrm{~d} \nu_{T+1}
\end{array}\right)=\left(\begin{array}{c}
\frac{1}{w_{T} l_{l_{T}}^{y}} \\
0
\end{array}\right) \mathrm{d} b_{T+1}, \quad\left(\begin{array}{c}
\mathrm{d} l_{t} \\
\mathrm{~d} \nu_{t+1}
\end{array}\right)=\left(\begin{array}{l}
0 \\
0
\end{array}\right) \text { for } \forall t \in[T+1, \infty] .
$$

The period- $T$ value of the additional tax imposed on the children when they are old is $\frac{1}{1+r_{T+1}} \mathrm{~d} z_{T+1}^{o}=\mathrm{d} b_{T+1}$. If full employment holds, it makes the children worse off since 
there is no room for employment expansion. However, in the presence of involuntary unemployment fiscal expansion financed by bond issuance stimulates aggregate demand and increases employment since from (12) and (23) where $k_{T}$ is predetermined we derive

$$
\mathrm{d} y_{T}=F_{l_{T}} \frac{1}{w_{T} l_{l_{T}}^{y}} \mathrm{~d} b_{T+1}, \quad \mathrm{~d} l_{T}=\frac{1}{w_{T} l_{l_{T}}^{y}} \mathrm{~d} b_{T+1} .
$$

Accordingly, the children earn additional labor income that exactly offsets the additional tax since (15) and the second equation above give

$$
w_{T} \mathrm{~d} l_{T}^{y}=w_{T} l_{l_{T}}^{y} \mathrm{~d} l_{T}=\mathrm{d} b_{T+1} .
$$

This result implies that the children's welfare is not affected by the bond issuance. The formal proof is as follows. Since from (23) $\mathrm{d} l_{T+1}=0, \mathrm{~d} \nu_{T+2}=0$ and $\mathrm{d} \nu_{T+1}=0$ and prices are invariant in the relevant periods, (14) in which $t=T+1$ and (17) in which $t=T$ respectively yield

$$
\begin{aligned}
\mathrm{d} r_{T+1} & =\frac{\epsilon_{T}}{\zeta_{T}} \mathrm{~d} l_{T+1}+\frac{1}{\zeta_{T}} \mathrm{~d} \nu_{T+2}-\frac{1+r_{T+1}}{\zeta_{T}} \mathrm{~d} \nu_{T+1}=0, \\
\mathrm{~d} \Omega_{T} & =-\frac{m_{r_{T+1}}+\left(1+\pi_{T+1}\right) m_{R_{T+1}}}{m_{\Omega_{T}}} \mathrm{~d} r_{T+1}=0, \\
\mathrm{~d} \pi_{T+1} & =0 .
\end{aligned}
$$

Therefore, from (1), (5), and (9)-(11) we derive

$$
\mathrm{d} c_{T}^{y}=0, \quad \mathrm{~d} c_{T+1}^{o}=0, \quad \mathrm{~d} U_{T}=0 .
$$

In sum, the parents (viz., the generation born in period $T-1$ ) receive income through either transfers or government purchases and use it up before they die (i.e., within period T). ${ }^{7}$ Hence, in the presence of Keynesian unemployment their children definitely enjoy an increase in labor income that exactly offsets the tax burden due to public bonds. From the second property of (23) with Policy 1, there is obviously no welfare effect on the grandchildren (viz., the generation born in period $T+1$ ). We summarize this result in the following proposition:

\footnotetext{
${ }^{7}$ As analyzed in Barro (1974), if the current generation chooses to bequeath a legacy to future generations due to altruistic motives, the Ricardian equivalence holds and an issue of public debt has no effect.
} 
Proposition 1. Under (19)-(22) and Policy 1 public debt places no burden on future generations.

Remark 1. If government purchases are used to build facilities that yield utility for future generations, they are better off by the magnitude of the utility.

Note that Policy 1 improves the welfare of the parents. To show it we combine (3) and (14) and obtain

$$
c_{T}^{o}=\frac{1}{1+\pi_{T}} m_{T-1}+\left(1+r_{T}\right) b_{T}+k_{T}+\nu_{T+1}+F\left(k_{T}, l_{T}\right)-w_{T} l_{T}+w_{T}\left[l_{T}-l^{y}\left(l_{T}\right)\right]-z_{T}^{o},
$$

where $k_{T}$ is predetermined. Totally differentiating this equation and applying (1), (20) and (23) into the result yields

$$
\begin{aligned}
\mathrm{d} c_{T}^{o} & =\left[\left(F_{l_{T}}-w_{T}\right)+w_{T}\left(1-l_{l_{T}}^{y}\right)\right] \mathrm{d} l_{T}-\mathrm{d} z_{T}^{o} \\
& =\frac{F_{l_{T}}-w_{T} l_{l_{T}}^{y}}{w_{T} l_{l_{T}}^{y}} \mathrm{~d} g_{T}-\frac{F_{l_{T}}}{w_{T} l_{l_{T}}^{y}} \mathrm{~d} z_{T}^{o}>0, \\
\mathrm{~d} U_{T-1} & =\theta u^{\prime}\left(c_{T}^{o}\right) \mathrm{d} c_{T}^{o}>0 .
\end{aligned}
$$

An increase in aggregate employment makes the parents better off since it raises not only the value of equities held by them but also their wage earnings. Those two effects are represented by the first and the second term of the coefficient of $\mathrm{d} l_{T}$ in (24), respectively. Direct transfer $-\mathrm{d} z_{T}^{o}(>0)$ obviously benefits them. Thus, Policy 1 makes them better off. The two expressions of $\mathrm{d} c_{T}^{o}$ in (24) imply that the welfare of the parents increases as the marginal expansion of their employment $\left(1-l_{l_{T}}^{y}\right)$ is larger, and that they receive a larger gain from direct transfer $-\mathrm{d} z_{T}^{o}$ than from government purchases $\mathrm{d} g_{T}$.

\subsection{Tax on Grandchildren}

We have so far considered the case where all the tax burden due to public debt rests on children. This section examines the case that a part of it is placed on grandchildren, which is broadly believed to make them worse off. To address this issue we consider the following policy in place of Policy 1 in the context of (19)-(22):

Policy 2. Public debt is redeemed by taxing on both the old and the young in period $T+1$ : $d z_{T+1}^{y}+d z_{T+1}^{o}=\left(1+r_{T+1}\right) d b_{T+1}(>0), d z_{T+1}^{o} \geq 0$, and $d z_{T+1}^{y}>0$. 
Note that this policy can be interpreted as a combination of Policy 1 and an income transfer from grandchildren to children in period $T+1$.

Under (19)-(22) and Policy 2 we have a unique consistent equilibrium that satisfies

$$
\left(\begin{array}{c}
\mathrm{d} l_{T+1} \\
\mathrm{~d} \nu_{T+2}
\end{array}\right)=\left(\begin{array}{c}
\frac{1}{w_{T+1} l_{l_{T+1}}^{y}} \\
0
\end{array}\right) \mathrm{d} z_{T+1}^{y}, \quad\left(\begin{array}{c}
\mathrm{d} l_{t} \\
\mathrm{~d} \nu_{t+1}
\end{array}\right)=\left(\begin{array}{l}
0 \\
0
\end{array}\right) \text { for } t \in[T+2, \infty] .
$$

With full employment the additional tax makes the grandchildren worse off by raising the children's consumption. In the presence of unemployment, however, the rise in the children's consumption increases the grandchildren's employment in period $T+1$. From (15) and (25), the additional labor income of the grandchildren is

$$
w_{T+1} \mathrm{~d} l_{T+1}^{y}=w_{T+1} l_{l_{T+1}}^{y} \mathrm{~d} l_{T+1}=\mathrm{d} z_{T+1}^{y},
$$

which exactly offsets their tax burden. Consequently, the grandchildren's welfare is unaffected whereas the children's welfare increases: The same mechanism as Proposition 1 works in period $T+1$. While the formal proof is given in Appendix $\mathrm{B}$, this property is summarized as follows:

Proposition 2. Under (19)-(22) and Policy 2 public debt issuance makes the generation born in period $T$ better off and the generations born in period $T+1$ and after unchanged. Thus, there is no burden on future generations.

Remark 2. The larger the marginal expansion of children's employment $\left(1-l_{l_{T+1}}^{y}\right)$ is, the greater their welfare is.

As for the parents' welfare, in Appendix $\mathrm{C}$ we obtain $\mathrm{d} c_{T}^{o}$ and $\mathrm{d} U_{T-1}$ :

$$
\begin{aligned}
\mathrm{d} c_{T}^{o} & =\frac{F_{l_{T}}-w_{T} l_{l_{T}}^{y}}{w_{T} l_{l_{T}}^{y}} \mathrm{~d} g_{T}-\frac{F_{l_{T}}}{w_{T} l_{l_{T}}^{y}} \mathrm{~d} z_{T}^{o}+\frac{\Phi_{T}}{\left(1+r_{T+1}\right) w_{T} l_{l_{T}}^{y} \Lambda_{T}} \mathrm{~d} z_{T+1}^{y} \gtreqless 0, \\
\mathrm{~d} U_{T-1} & =\theta u^{\prime}\left(c_{T}^{o}\right) \mathrm{d} c_{T}^{o} \gtreqless 0,
\end{aligned}
$$

where $\Lambda_{T}$ is positive but $\Phi_{T}$ can be positive or negative. Thus, public debt may or may not make the parents worse off. ${ }^{8}$

\footnotetext{
${ }^{8}$ Rankin (1986, pp. 497-498) imposes saddle-point stability and some other assumptions to show that public debt issuance raises output and welfare in steady state. Diamond (1965) also assumes saddlepoint stability to show that public debt burden arises under full employment. Similarly, we need some assumptions to show that public debt issuance makes the current generation better off.
} 


\section{Deficit-Covering Bonds}

This section examines the implication of deficit-covering bonds issued to redeem bonds. The amount of public bonds is zero for any point in time on the original path and is unanticipatedly increased in period $T$ by $\mathrm{d} b_{T+1}(>0)$ to finance government purchases and transfers to the old. Additional bonds are issued in period $T+1$ by $\mathrm{d} b_{T+2}(>0)$ to cover fiscal deficits and are redeemed in period $T+2$ by collecting taxes from the old and the young. That is,

$$
\begin{aligned}
\left\{\mathrm{d} b_{t}\right\}_{t=0}^{\infty} & =\left(0, \ldots, 0, \mathrm{~d} b_{T+1}, \mathrm{~d} b_{T+2}, 0, \ldots, 0\right), \\
\mathrm{d} b_{T+1} & =\mathrm{d} g_{T}-\mathrm{d} z_{T}^{o}, \\
\mathrm{~d} b_{T+2}+\mathrm{d} z_{T+1}^{y}+\mathrm{d} z_{T+1}^{o} & =\left(1+r_{T+1}\right) \mathrm{d} b_{T+1}, \\
\mathrm{~d} z_{T+2}^{y}+\mathrm{d} z_{T+2}^{o} & =\left(1+r_{T+2}\right) \mathrm{d} b_{T+2} .
\end{aligned}
$$

To focus on the pure effect of the additional bond issuance on the future generations, this section assumes that the tax-cum-subsidy on the young $\mathrm{d} z_{T+2}^{y}$ is adjusted in period $T+2$ lest the dynamic system for subsequent period $t \in[T+3, \infty]$ should change from the original one. Such $\mathrm{d} z_{T+2}^{y}$ is obtained by substituting $\mathrm{d} l_{T+3}=0$ and $\mathrm{d} \nu_{T+4}=0$ into the dynamics (18) for $t=T+2$ :

$$
\mathrm{d} z_{T+2}^{y}=w_{T+2} l_{l_{T+2}}^{y} \mathrm{~d} l_{T+2}, \quad \mathrm{~d} \nu_{T+3}=0 .
$$

In addition, this section imposes the following policy to obtain the pure welfare effect of the additional bond issuance.

Policy 3. Public debt is redeemed by taxing on only the old in period $T+2: d z_{T+2}^{o}=$ $\left(1+r_{T+2}\right) d b_{T+2}(>0)$ and $d z_{T+2}^{y}=0$.

Under (26)-(30) and Policy 3, additional bond issuance yields a tax burden on the grandchildren when they are old whereas there is no welfare effect on the generations born 
in period $t \in[T+2, \infty]$. The consistent equilibrium must satisfy

$$
\begin{aligned}
& \left(\begin{array}{c}
\mathrm{d} l_{T+1} \\
\mathrm{~d} \nu_{T+2}
\end{array}\right)=\left(\begin{array}{c}
\frac{1}{w_{T+1} l_{T+1}^{y}} \\
0
\end{array}\right)\left(\mathrm{d} b_{T+2}+\mathrm{d} z_{T+1}^{y}\right), \\
& \left(\begin{array}{c}
\mathrm{d} l_{t} \\
\mathrm{~d} \nu_{t+1}
\end{array}\right)=\left(\begin{array}{l}
0 \\
0
\end{array}\right) \text { for } t \in[T+2, \infty] .
\end{aligned}
$$

By comparing (25) and (31) we find that the implication of Proposition 2 is valid in Proposition 3 and that deficit-covering bonds play exactly the same role as the tax on the grandchildren when young $\left(\mathrm{d} z_{T+1}^{y}\right)$. Issuing additional bonds in period $T+1$ generates an income transfer from the grandchildren to the children in the form of tax reduction and the children increase consumption. Since the children use up all the gains before they die (i.e., within period $T+1$ ), the grandchildren definitely receive the additional income that exactly covers the additional tax burden. Thus, the welfare of the grandchildren is unaffected by the additional bond issuance whereas the children are better off.

We summarize the above result in the following:

Proposition 3. Under (26)-(30) and Policy 3, issuance of deficit-covering bonds enhances the welfare of the generation born in period $T$ while leaving unchanged the welfare of the generations born in period $T+1$ and after. Public debt thus places no burden on future generations.

The welfare effect on the parents is ambiguous for the same reason as discussed below Proposition 2. ${ }^{9}$ If public bonds are permanently rolled over, Rankin's (1986) result on the steady-state welfare is duplicated. ${ }^{10}$ Rankin imposes some conditions to show that a permanent increase in public debt raises the steady-state welfare. In contrast, we show that bond issuance always places no burden on future generations while it may or may not make the current generation better off. This result is consistent with Rankin's since the effect on the steady-state welfare is a mixture of the two.

\footnotetext{
${ }^{9}$ See Appendix $\mathrm{C}$ for the formal proof.

${ }^{10}$ As already mentioned in Footnote 3, we explicitly introduce equities whereas Rankin (1986) assumes that the ownership of firms is always in the hands of the old. Thus, there is a slight difference between the results of the two.
} 


\section{Conclusion}

Government purchases and transfers to the present generation financed by public debt issuance require additional taxes on future generations and thereby make them worse off as long as full employment always holds, as shown in the literature. If there are demand shortages and involuntary unemployment at least in the periods in which bonds are issued and redeemed, however, the future generations who are taxed to redeem the bonds earn a large enough wage income to cover the additional tax burden while the economic situations of the subsequent generations are unaffected. Thus, there is no debt burden on future generations. This result still holds even if deficit-covering bonds are issued and the additional taxes are imposed on yet unborn generations. 


\section{Appendices}

\section{Appendix A The Property of Demand Functions}

This appendix derives the properties of demand functions (9)-(11). Totally differentiating (4), (7) and (8) yields

$$
\begin{aligned}
c_{\Omega_{t}}^{y} & =\frac{1}{\Gamma_{t}}>0 \\
c_{r_{t+1}}^{y} & =\frac{u^{\prime}\left(c_{t+1}^{o}\right)}{\Gamma_{t}\left(1+r_{t+1}\right)^{2} u^{\prime \prime}\left(c_{t+1}^{o}\right)}\left[1-\left(-\frac{\left.u^{\prime \prime}\left(c_{t+1}^{o}\right) c_{t+1}^{o}\right)}{u^{\prime}\left(c_{t+1}^{o}\right)}\right)\right], \\
c_{R_{t+1}}^{y} & =-\frac{v^{\prime}\left(m_{t}\right)}{\Gamma_{t}\left(1+R_{t+1}\right)^{2} v^{\prime \prime}\left(m_{t}\right)}\left[1-\left(-\frac{v^{\prime \prime}\left(m_{t}\right) m_{t}}{v^{\prime}\left(m_{t}\right)}\right)\right], \\
m_{\Omega_{t}} & =\Delta_{t} c_{\Omega_{t}}^{y}>0 \\
m_{r_{t+1}} & =\Delta_{t} c_{r_{t+1}}^{y}, \\
m_{R_{t+1}} & =\Delta_{t}\left[c_{R_{t+1}}^{y}+\frac{v^{\prime}\left(m_{t}\right)}{R_{t+1}^{2} u^{\prime \prime}\left(c_{t}^{y}\right)}\right] \\
& =\frac{m_{\Omega_{t}} v^{\prime}\left(m_{t}\right)}{\left(1+R_{t+1}\right)^{2}}\left[-\frac{m_{t}}{v^{\prime}\left(m_{t}\right)}+\frac{\left(1+R_{t+1}\right)^{2}}{R_{t+1}^{2} u^{\prime \prime}\left(c_{t}^{y}\right)}+\frac{\left(1+R_{t+1}\right)^{2}}{\left(1+r_{t+1}\right)^{2} R_{t+1}^{2} \theta u^{\prime \prime}\left(c_{t+1}^{o}\right)}\right]<0,
\end{aligned}
$$

where

$$
\begin{aligned}
\Gamma_{t} & \equiv 1+\frac{R_{t+1}^{2} u^{\prime \prime}\left(c_{t}^{y}\right)}{\left(1+R_{t+1}\right)^{2} v^{\prime \prime}\left(m_{t}\right)}+\frac{u^{\prime \prime}\left(c_{t}^{y}\right)}{\left(1+r_{t+1}\right)^{2} \theta u^{\prime \prime}\left(c_{t+1}^{o}\right)}>1 \\
\Delta_{t} & \equiv \frac{R_{t+1} u^{\prime \prime}\left(c_{t}^{y}\right)}{\left(1+R_{t+1}\right) v^{\prime \prime}\left(m_{t}\right)}>0 .
\end{aligned}
$$

Hence, we have

$$
\begin{aligned}
& 1-c_{\Omega_{t}}^{y}=\frac{\Gamma_{t}-1}{\Gamma_{t}}>0, \\
& -c_{\Omega_{t}}^{y}\left[m_{r_{t+1}}+\left(1+\pi_{t+1}\right) m_{R_{t+1}}\right]+m_{\Omega_{t}}\left[c_{r_{t+1}}^{y}+\left(1+\pi_{t+1}\right) c_{R_{t+1}}^{y}\right]=-\frac{\left(1+\pi_{t+1}\right) m_{\Omega_{t}} v^{\prime}\left(m_{t}\right)}{R_{t+1}^{2} u^{\prime \prime}\left(c_{t}^{y}\right)}>0 .
\end{aligned}
$$

\section{Appendix B The Proof of Proposition 2}

Because $\mathrm{d} z_{T}^{y}=0$ and $\mathrm{d} z_{T+1}^{o}=\left(1+r_{T+1}\right) \mathrm{d} b_{T+1}-\mathrm{d} z_{T+1}^{y}$ from (20) and (21), the dynamics given by (18) for $t=T$ is

$$
A_{T}\left(\begin{array}{c}
\mathrm{d} l_{T+1} \\
\mathrm{~d} \nu_{T+2}
\end{array}\right)=B_{T}\left(\begin{array}{c}
\mathrm{d} l_{T} \\
\mathrm{~d} \nu_{T+1}
\end{array}\right)+\left(\begin{array}{cc}
1-c_{\Omega_{T}}^{y} & \frac{c_{\Omega_{T}}^{y}}{1+r_{T+1}} \\
-m_{\Omega_{T}} & \frac{m_{\Omega_{T}}}{1+r_{T+1}}
\end{array}\right)\left(\begin{array}{c}
\mathrm{d} b_{T+1} \\
\mathrm{~d} z_{T+1}^{y}
\end{array}\right) .
$$


Under (19)-(22) and Policy 2 we have a unique consistent equilibrium

$$
\begin{aligned}
\left(\begin{array}{c}
\mathrm{d} l_{T} \\
\mathrm{~d} \nu_{T+1}
\end{array}\right) & =\left(\begin{array}{c}
\frac{1}{w_{T} l_{l_{T}}^{y}} \\
0
\end{array}\right) \mathrm{d} b_{T+1}+\frac{1}{w_{T+1} l_{l_{T+1}}^{y}} D_{T} \mathrm{~d} z_{T+1}^{y}, \\
\left(\begin{array}{c}
\mathrm{d} l_{T+1} \\
\mathrm{~d} \nu_{T+2}
\end{array}\right) & =\left(\begin{array}{c}
\frac{1}{w_{T+1} l_{l_{T+1}}^{y}} \\
0
\end{array}\right) \mathrm{d} z_{T+1}^{y}, \\
\left(\begin{array}{c}
\mathrm{d} l_{t} \\
\mathrm{~d} \nu_{t+1}
\end{array}\right) & =\left(\begin{array}{l}
0 \\
0
\end{array}\right) \text { for } t \in[T+2, \infty],
\end{aligned}
$$

where

$$
D_{t} \equiv B_{t}^{-1}\left(\begin{array}{c}
-\frac{c_{\Omega_{t}}^{y} w_{t+1} l_{l_{t+1}}^{y}}{1+r_{t+1}}+\frac{\alpha_{t} \zeta_{t}-\beta_{t} \epsilon_{t}}{\zeta_{t}} \\
-\frac{m_{\Omega_{t}} w_{t+1} l_{l_{t+1}}^{y}}{1+r_{t+1}}+\frac{\gamma_{t} \zeta_{t}-\delta_{t} \epsilon_{t}}{\zeta_{t}}
\end{array}\right) .
$$

Since the utility levels of the generations born in period $t \in[T+1, \infty]$ are not affected by bond issuance under (19)-(22) and Policy 2, it is sufficient to examine only the welfare effect on the children. Linearizing (14) in which $t=T+1$ and applying (A.2) to the result yields

$$
\begin{aligned}
\mathrm{d} r_{T+1} & =\frac{\epsilon_{T}}{\zeta_{T}} \mathrm{~d} l_{T+1}+\frac{1}{\zeta_{T}} \mathrm{~d} \nu_{T+2}-\frac{1+r_{T+1}}{\zeta_{T}} \mathrm{~d} \nu_{T+1} \\
& =-\frac{F_{l_{T+1}}+\left(1+F_{k_{T+1}}\right) k_{l_{T+1}}}{w_{T+1} l_{l_{T+1}}^{y}\left[\frac{\left(1+R_{T+1}\right) u^{\prime}\left(c_{T+1}^{o}\right)}{R_{T+1}\left(1+r_{T+1}\right) u^{\prime \prime}\left(c_{T+1}^{o}\right)}+\left(1+F_{k_{T+1}}\right) k_{r_{T+1}}\right]} \mathrm{d} z_{T+1}^{y}>0,
\end{aligned}
$$

where $\epsilon_{T}$ and $\zeta_{T}$ are given below (18). From (17) we obtain

$$
\mathrm{d} \Omega_{T}=-\frac{m_{r_{T+1}}+\left(1+\pi_{T+1}\right) m_{R_{T+1}}}{m_{\Omega_{T}}} \mathrm{~d} r_{T+1}
$$

Equations (5), (9) and the above equation lead to

$$
\begin{aligned}
\mathrm{d} c_{T}^{y} & =c_{\Omega_{T}}^{y} \mathrm{~d} \Omega_{T}+\left[c_{r_{T+1}}^{y}+\left(1+\pi_{T+1}\right) c_{R_{T+1}}^{y}\right] \mathrm{d} r_{T+1} \\
& =\frac{-c_{\Omega_{t}}^{y}\left[m_{r_{t+1}}+\left(1+\pi_{t+1}\right) m_{R_{t+1}}\right]+m_{\Omega_{t}}\left[c_{r_{t+1}}^{y}+\left(1+\pi_{t+1}\right) c_{R_{t+1}}^{y}\right]}{m_{\Omega_{T}}} \mathrm{~d} r_{T+1}>0
\end{aligned}
$$

where the sign of the numerator is given by (A.1). Since $u^{\prime}>0$ and $u^{\prime \prime}<0$, from (7), (A.3) and (A.4) we obtain

$$
\mathrm{d} c_{T+1}^{o}=\frac{u^{\prime \prime}\left(c_{T}^{y}\right)}{\left(1+r_{T+1}\right) \theta u^{\prime \prime}\left(c_{T+1}^{o}\right)} \mathrm{d} c_{T}^{y}-\frac{u^{\prime}\left(c_{T+1}^{o}\right)}{\left(1+r_{T+1}\right) u^{\prime \prime}\left(c_{T+1}^{o}\right)} \mathrm{d} r_{T+1}>0 .
$$


Accordingly, (1), (A.4) and (A.5) give

$$
\mathrm{d} U_{T}=u^{\prime}\left(c_{T}^{y}\right) \mathrm{d} c_{T}^{y}+\theta u^{\prime}\left(c_{T+1}^{o}\right) \mathrm{d} c_{T+1}^{o}>0 .
$$

Since a decrease in $l_{l_{T+1}}^{y}$ raises $\mathrm{d} r_{T+1}$ given by (A.3), it increases $\mathrm{d} c_{T}^{y}$ in (A.4) and $\mathrm{d} c_{T+1}^{o}$ in (A.5) and hence increases $\mathrm{d} U_{T}$, implying Remark 2.

\section{Appendix C The Welfare Effect of Public Debt on Parents under (19)-(22) and Policy 2}

This appendix shows that the welfare effect of public debt on parents depends on the signs of $\mathrm{d} \nu_{T+1}$ and $\mathrm{d} l_{T}$, which are ambiguous. Totally differentiating (14) where $t=T+1$ and substituting (25) into the result gives

$$
\begin{aligned}
\mathrm{d} \nu_{T+1} & =\frac{\epsilon_{T}}{1+r_{T+1}} \mathrm{~d} l_{T+1}+\frac{1}{1+r_{T+1}} \mathrm{~d} \nu_{T+2}-\frac{\zeta_{T}}{1+r_{T+1}} \mathrm{~d} r_{T+1} \\
& =\frac{\epsilon_{T}}{\left(1+r_{T+1}\right) w_{T+1} l_{l_{T+1}}^{y}} \mathrm{~d} z_{T+1}^{y}-\frac{\zeta_{T}}{1+r_{T+1}} \mathrm{~d} r_{T+1},
\end{aligned}
$$

where $\epsilon_{T}(>0)$ and $\zeta_{T}(>0)$ are given below (18). An income transfer from the grandchildren to the children, $\mathrm{d} z_{T+1}^{y}>0$, directly increases labor employment $\mathrm{d} l_{T+1}$ and firm value $\mathrm{d} \nu_{T+1}$. It also raises the interest rate (as shown in (A.3)), which in turn reduces $\mathrm{d} \nu_{T+1}$. Accordingly, the total effect on $\mathrm{d} \nu_{T+1}$ is ambiguous. In fact, substituting (A.3) into (A.6) yields

$$
\mathrm{d} \nu_{T+1}=\frac{\Theta_{T}}{\left(1+r_{T+1}\right) \Lambda_{T}} \mathrm{~d} z_{T+1}^{y} \gtreqless 0,
$$

where

$$
\begin{aligned}
\Theta_{T} \equiv & \frac{\left[\left(F_{k_{T+1}}-r_{T+1}\right) k_{l_{T+1}}+\left(F_{l_{T+1}}-w_{T+1}\right)\right]\left(1+R_{T+1}\right) c_{T+1}^{o}}{R_{T+1}\left(1+r_{T+1}\right)}\left(-\frac{u^{\prime}\left(c_{T+1}^{o}\right)}{u^{\prime \prime}\left(c_{T+1}^{o}\right) c_{T+1}^{o}}\right) \\
& -\left(F_{l_{T+1}}-w_{T+1}\right) k_{r_{T+1}}-\left(\nu_{T+1}+k_{T+1}\right)\left[\left(1+F_{k_{T+1}}\right) k_{l_{T+1}}+F_{l_{T+1}}\right] \gtreqless 0, \\
\Lambda_{T} \equiv & -w_{T+1} l_{l_{T+1}}^{y}\left[\frac{\left(1+R_{T+1}\right) u^{\prime}\left(c_{T+1}^{o}\right)}{R_{T+1}\left(1+r_{T+1}\right) u^{\prime \prime}\left(c_{T+1}^{o}\right)}+\left(1+F_{k_{T+1}}\right) k_{r_{T+1}}\right]>0 .
\end{aligned}
$$

Note that this is the same as $\mathrm{d} \nu_{T+1}$ given in (A.2). The denominator of (A.7) is positive and thus the sign of $\Theta_{T}$ determines the sign of $\mathrm{d} \nu_{T+1}$. 
Totally differentiating (16) where $t=T$ and substituting (20), (25), and (A.6) into the result generates

$$
\begin{aligned}
\mathrm{d} l_{T}= & \frac{-\alpha_{T}}{\left(1-c_{\Omega_{T}}^{y}\right) w_{T} l_{l_{T}}^{y}} \mathrm{~d} l_{T+1}+\frac{1}{\left(1-c_{\Omega_{T}}^{y}\right) w_{T} l_{l_{T}}^{y}} \mathrm{~d} \nu_{T+1}+\frac{\beta_{T}}{\left(1-c_{\Omega_{T}}^{y}\right) w_{T} l_{l_{T}}^{y}} \mathrm{~d} r_{T+1} \\
& +\frac{1}{w_{T} l_{l_{T}}^{y}} \mathrm{~d} b_{T+1}+\frac{c_{\Omega_{T}}^{y}}{\left(1-c_{\Omega_{T}}^{y}\right)\left(1+r_{T+1}\right) w_{T} l_{l_{T}}^{y}} \mathrm{~d} z_{T+1}^{y} \\
= & \frac{1}{w_{T} l_{l_{T}}^{y}}\left(\mathrm{~d} g_{T}-\mathrm{d} z_{T}^{o}\right)+\frac{w_{T+1} l_{l_{T+1}}^{y} c_{\Omega_{T}}^{y}-\left(1+r_{T+1}\right) \alpha_{T}+\epsilon_{T}}{\left(1-c_{\Omega_{T}}^{y}\right)\left(1+r_{T+1}\right) w_{T} l_{l_{T}}^{y} w_{T+1} l_{l_{T+1}}^{y}} \mathrm{~d} z_{T+1}^{y} \\
& +\frac{\left(1+r_{T+1}\right) \beta_{T}-\zeta_{T}}{\left(1-c_{\Omega_{T}}^{y}\right)\left(1+r_{T+1}\right) w_{T} l_{l_{T}}^{y}} \mathrm{~d} r_{T+1},
\end{aligned}
$$

where $\alpha_{T}(<0), \beta_{T}, \epsilon_{T}(>0)$, and $\zeta_{T}(>0)$ are given below (18). Thus, while the income transfer from the grandchildren to the children directly increases labor employment $\mathrm{d} l_{T}$, it also raises the interest rate (see (A.3)), which makes the effect on $\mathrm{d} l_{T}$ ambiguous. In fact, substituting (A.3) into the above equation gives

$$
\mathrm{d} l_{T}=\frac{1}{w_{T} l_{l_{T}}^{y}}\left(\mathrm{~d} g_{T}-\mathrm{d} z_{T}^{o}\right)+\frac{\Xi_{T}}{\left(1+r_{T+1}\right) w_{T} l_{l_{T}}^{y} \Lambda_{T}} \mathrm{~d} z_{T+1}^{y} \gtreqless 0,
$$

where

$$
\begin{aligned}
\Xi_{T} \equiv & \frac{\left[\left(1+F_{k_{T+1}}\right) k_{l_{T+1}}+F_{l_{T+1}}\right] c_{T}^{y}}{R_{T+1}}\left(-\frac{u^{\prime}\left(c_{T}^{y}\right)}{u^{\prime \prime}\left(c_{T}^{y}\right) c_{T}^{y}}\right) \\
& +\frac{\left[\left(1+F_{k_{T+1}}\right) k_{l_{T+1}}+\left(F_{l_{T+1}}-w_{T+1}\right)\right]\left(1+R_{T+1}\right) c_{T+1}^{o}}{R_{T+1}\left(1+r_{T+1}\right)}\left(-\frac{u^{\prime}\left(c_{T+1}^{o}\right)}{u^{\prime \prime}\left(c_{T+1}^{o}\right) c_{T+1}^{o}}\right) \\
& +w_{T+1}\left(1+F_{l_{T+1}}\right) k_{r_{T+1}}-\left(\nu_{T+1}+k_{T+1}\right)\left[\left(1+F_{k_{T+1}}\right) k_{l_{T+1}}+F_{l_{T+1}}\right] \gtreqless 0 .
\end{aligned}
$$

Note that this is the same as $\mathrm{d} l_{T}$ given in (A.2). Under (19)-(22) and Policy $2, \mathrm{~d} z_{T+1}^{y}$ is in the following range:

$$
0<\mathrm{d} z_{T+1}^{y} \leq\left(1+r_{T+1}\right) \mathrm{d} b_{T+1}=\left(1+r_{T+1}\right)\left(\mathrm{d} g_{T}-\mathrm{d} z_{T}^{o}\right)
$$

If $\Xi_{T}$ is positive, public debt issuance unambiguously increases labor employment $\mathrm{d} l_{T}$. If $\Xi_{T}$ is negative, in the case of $\mathrm{d} z_{T+1}^{y}=\left(1+r_{T+1}\right)\left(\mathrm{d} g_{T}-\mathrm{d} z_{T}^{o}\right), \mathrm{d} l_{T}$ takes its lower bound $\left(\mathrm{d} \hat{l}_{T}\right)$ and may become negative. It is given by

$$
\mathrm{d} \hat{l}_{T}=\frac{\Upsilon_{T}}{w_{T} l_{l_{T}}^{y} \Lambda_{T}}\left(\mathrm{~d} g_{T}-\mathrm{d} z_{T}^{o}\right)
$$


where

$$
\begin{aligned}
\Upsilon_{T} \equiv & \frac{\left[\left(1+F_{k_{T+1}}\right) k_{l_{T+1}}+F_{l_{T+1}}\right] c_{T}^{y}}{R_{T+1}}\left(-\frac{u^{\prime}\left(c_{T}^{y}\right)}{u^{\prime \prime}\left(c_{T}^{y}\right) c_{T}^{y}}\right) \\
& +\frac{\left\{\left(1+F_{k_{T+1}}\right) k_{l_{T+1}}+\left[F_{l_{T+1}}-w_{T+1}\left(1-l_{l_{T+1}}^{y}\right)\right]\right\}\left(1+R_{T+1}\right) c_{T+1}^{o}}{R_{T+1}\left(1+r_{T+1}\right)}\left(-\frac{u^{\prime}\left(c_{T+1}^{o}\right)}{u^{\prime \prime}\left(c_{T+1}^{o}\right) c_{T+1}^{o}}\right) \\
& +w_{T+1}\left(1-l_{l_{T+1}}^{y}\right)\left(1+F_{l_{T+1}}\right) k_{r_{T+1}}-\left(\nu_{T+1}+k_{T+1}\right)\left[\left(1+F_{k_{T+1}}\right) k_{l_{T+1}}+F_{l_{T+1}}\right] \gtreqless 0 .
\end{aligned}
$$

If $\Upsilon_{T}$ is positive, the total effect on $\mathrm{d} l_{T}$ is always positive. If $\Upsilon_{T}$ is negative, $\mathrm{d} \hat{l}_{T}$ is negative and thus the total effect on $\mathrm{d} l_{T}$ is ambiguous depending on the magnitude of $\mathrm{d} z_{T+1}^{y}$.

From (1), (3), (14), (A.7), and (A.8), we obtain

$$
\begin{aligned}
\mathrm{d} c_{T}^{o} & =\mathrm{d} \nu_{T+1}+\left[\left(F_{l_{T}}-w_{T}\right)+w_{T}\left(1-l_{l_{T}}^{y}\right)\right] \mathrm{d} l_{T}-\mathrm{d} z_{T}^{o} \\
& =\frac{F_{l_{T}}-w_{T} l_{l_{T}}^{y}}{w_{T} l_{l_{T}}^{y}} \mathrm{~d} g_{T}-\frac{F_{l_{T}}}{w_{T} l_{l_{T}}^{y}} \mathrm{~d} z_{T}^{o}+\frac{\Phi_{T}}{\left(1+r_{T+1}\right) w_{T} l_{l_{T}}^{y} \Lambda_{T}} \mathrm{~d} z_{T+1}^{y} \gtreqless 0, \\
\mathrm{~d} U_{T-1} & =\theta u^{\prime}\left(c_{T}^{o}\right) \mathrm{d} c_{T}^{o} \gtreqless 0,
\end{aligned}
$$

where

$$
\begin{aligned}
\Phi_{T} \equiv & \frac{\left(F_{l_{T}}-w_{T} l_{l_{T}}^{y}\right)\left[\left(1+F_{k_{T+1}}\right) k_{l_{T+1}}+F_{l_{T+1}}\right] c_{T}^{y}}{R_{T+1}}\left(-\frac{u^{\prime}\left(c_{T}^{y}\right)}{u^{\prime \prime}\left(c_{T}^{y}\right) c_{T}^{y}}\right)+\phi_{T}\left(-\frac{u^{\prime}\left(c_{T+1}^{o}\right)}{u^{\prime \prime}\left(c_{T+1}^{o}\right) c_{T+1}^{o}}\right) \\
& +\left[F_{l_{T}} w_{T+1}\left(1+F_{k_{T+1}}\right)-w_{T} l_{l_{T}}^{y} F_{l_{T+1}}\left(1+r_{T+1}\right)\right] k_{r_{T+1}} \\
& -\left(\nu_{T+1}+k_{T+1}\right) F_{l_{T}}\left[\left(1+F_{k_{T+1}}\right) k_{l_{T+1}}+F_{l_{T+1}}\right] \gtreqless 0, \\
\phi_{T} \equiv & \frac{\left[F_{l_{T}}\left(1+F_{k_{T+1}}\right)-w_{T} l_{l_{T}}^{y}\left(1+r_{T+1}\right)\right] k_{l_{T+1}}+F_{l_{T}}\left(F_{l_{T+1}}-w_{T+1}\right)}{R_{T+1}\left(1+r_{T+1}\right)\left[\left(1+R_{T+1}\right) c_{T+1}^{o}\right]^{-1}}>0 .
\end{aligned}
$$

If $\Phi_{T}$ is positive, public debt issuance is unambiguously beneficial to parents. If $\Phi_{T}$ is negative, the case of $\mathrm{d} z_{T+1}^{y}=\left(1+r_{T+1}\right)\left(\mathrm{d} g_{T}-\mathrm{d} z_{T}^{o}\right)$ gives the lower bound of $\mathrm{d} c_{T}^{o}\left(\mathrm{~d} \hat{c}_{T}^{o}\right)$, which may become negative. It is given by

$$
\mathrm{d} \hat{c}_{T}^{o}=\frac{\Psi_{T}^{g}}{w_{T} l_{l_{T}}^{y} \Lambda_{T}} \mathrm{~d} g_{T}-\frac{\Psi_{T}^{z}}{w_{T} l_{l_{T}}^{y} \Lambda_{T}} \mathrm{~d} z_{T}^{o},
$$

where

$$
\begin{aligned}
\Psi_{T}^{g} \equiv & \frac{\left(F_{l_{T}}-w_{T} l_{l_{T}}^{y}\right)\left[\left(1+F_{k_{T+1}}\right) k_{l_{T+1}}+F_{l_{T+1}}\right] c_{T}^{y}}{R_{T+1}}\left(-\frac{u^{\prime}\left(c_{T}^{y}\right)}{u^{\prime \prime}\left(c_{T}^{y}\right) c_{T}^{y}}\right)+\psi_{T}^{g c}\left(-\frac{u^{\prime}\left(c_{T+1}^{o}\right)}{u^{\prime \prime}\left(c_{T+1}^{o}\right) c_{T+1}^{o}}\right) \\
& -\psi_{T}^{g k} k_{r_{T+1}}-\left(\nu_{T+1}+k_{T+1}\right) F_{l_{T}}\left[\left(1+F_{k_{T+1}}\right) k_{l_{T+1}}+F_{l_{T+1}}\right] \gtreqless 0,
\end{aligned}
$$




$$
\begin{gathered}
\psi_{T}^{g c} \equiv \frac{\left[F_{l_{T}}\left(1+F_{k_{T+1}}\right)-w_{T} l_{l_{T}}^{y}\left(1+r_{T+1}\right)\right] k_{l_{T+1}}+F_{l_{T}}\left(F_{l_{T+1}}-w_{T+1}\right)+w_{T+1} l_{l_{T+1}}^{y}\left(F_{l_{T}}-w_{T} l_{l_{T}}^{y}\right)}{R_{T+1}\left(1+r_{T+1}\right)\left[\left(1+R_{T+1}\right) c_{T+1}^{o}\right]^{-1}}>0, \\
\psi_{T}^{g k} \equiv w_{T} l_{l_{T}}^{y}\left[\left(F_{l_{T+1}}-w_{T+1} l_{l_{T+1}}^{y}\right)+w_{T+1} F_{k_{T+1}}\left(1-l_{l_{T+1}}^{y}\right)\right]-F_{l_{T}} w_{T+1}\left(1-l_{l_{T+1}}^{y}\right)\left(1+F_{k_{T+1}}\right) \gtreqless 0,
\end{gathered}
$$

and

$$
\begin{gathered}
\Psi_{T}^{z} \equiv \frac{\left(F_{l_{T}}-w_{T} l_{l_{T}}^{y}\right)\left[\left(1+F_{k_{T+1}}\right) k_{l_{T+1}}+F_{l_{T+1}}\right] c_{T}^{y}}{R_{T+1}}\left(-\frac{u^{\prime}\left(c_{T}^{y}\right)}{u^{\prime \prime}\left(c_{T}^{y}\right) c_{T}^{y}}\right)+\psi_{T}^{z c}\left(-\frac{u^{\prime}\left(c_{T+1}^{o}\right)}{u^{\prime \prime}\left(c_{T+1}^{o}\right) c_{T+1}^{o}}\right) \\
-\psi_{T}^{z k} k_{r_{T+1}}-\left(\nu_{T+1}+k_{T+1}\right) F_{l_{T}}\left[\left(1+F_{k_{T+1}}\right) k_{l_{T+1}}+F_{l_{T+1}}\right] \gtreqless 0, \\
\psi_{T}^{z c} \equiv \frac{\left[F_{l_{T}}\left(1+F_{k_{T+1}}\right)-w_{T} l_{l_{T}}^{y}\left(1+r_{T+1}\right)\right] k_{l_{T+1}}+F_{l_{T}}\left[F_{l_{T+1}}-w_{T+1}\left(1-l_{l_{T+1}}^{y}\right)\right]}{R_{T+1}\left(1+r_{T+1}\right)\left[\left(1+R_{T+1}\right) c_{T+1}^{o}\right]^{-1}}>0, \\
\psi_{T}^{z k} \equiv w_{T} l_{l_{T}}^{y} F_{l_{T+1}}\left(1+r_{T+1}\right)-F_{l_{T}} w_{T+1}\left[\left(1-l_{l_{T+1}}^{y}\right)+F_{k_{T+1}}\right] \gtreqless 0 .
\end{gathered}
$$

If $\Psi_{T}^{g}$ is positive, government purchases financed by public bonds always make parents better off. If $\Psi_{T}^{g}$ is negative, the total welfare effect of government purchases on parents is ambiguous depending on the magnitude of $\mathrm{d} z_{T+1}^{y}$. Similarly, the subsidy to parents financed by public bonds may or may not improve the welfare of parents depending on the sign of $\Psi_{T}^{z}$ and the magnitude of $\mathrm{d} z_{T+1}^{y}$. Consequently, we conclude that the welfare effect of public debt on parents is ambiguous under (19)-(22) and Policy 2. By replacing $\mathrm{d} z_{T+1}^{y}$ with $\mathrm{d} b_{T+2}+\mathrm{d} z_{T+1}^{y}$ in (A.9), we find the welfare effect of public debt on parents to be ambiguous under (26)-(30) and Policy 3. 


\section{References}

Ball, L., D.W. Elmendorf, and N.G. Mankiw, "The Deficit Gamble," Journal of Money, Credit, and Banking 30 (1998), 699-720.

Barro, R.J., "Are Government Bonds Net Wealth?," Journal of Political Economy 82 (1974), 1095-1117.

Bernheim, B.D., "Ricardian Equivalence: An Evaluation of Theory and Evidence," in NBER Macroeconomics Annual, S. Fischer ed. (MIT Press: Cambridge, MA, 1987), 263-304.

Blanchard, O.J., "Debt, Deficits, and Finite Horizons," Journal of Political Economy 93 (1985), 223-247.

Blanchard, O.J., and P. Weil, "Dynamic Efficiency, the Riskless Rate, and Debt Ponzi Games under Uncertainty," Advances in Macroeconomics 1 (2001), 5-27.

Bohn, H., "The Sustainability of Budget Deficits in a Stochastic Economy," Journal of Money, Credit, and Banking 27 (1995), 257-271.

Buiter, W.H., "Death, Birth, Productivity Growth and Debt Neutrality," Economic Journal 98 (1988), 279-293.

Chalk, N.A., "The Sustainability of Bond-Financed Deficits: An Overlapping Generations Approach," Journal of Monetary Economics 45 (2000), 293-328.

Diamond, P.A., "National Debt in a Neoclassical Growth Model," American Economic Review 55 (1965), 1126-1150.

Drazen, A., "Government Debt, Human Capital, and Bequests in a Life-Cycle Model," Journal of Political Economy 86 (1978), 505-516.

Ganelli, G., "The New Open Economy Macroeconomics of Government Debt," Journal of International Economics 65 (2005), 167-184. 
Josten, S.D., "Dynamic Fiscal Policies and Unemployment in a Simple Endogenous Growth Model," International Tax and Public Finance 13 (2006), 701-716.

Kaas, L., and L. von Thadden, "Budgetary Policy and Unemployment Dynamics in an OLG Model with Collective Bargaining," Economic Journal 114 (2004), 867-889.

Lapan, H.E., and W. Enders "Endogenous Fertility, Ricardian Equivalence, and Debt Management Policy," Journal of Public Economics 41 (1990), 227-248.

Lopez-Garcia, MA., "On the Role of Public Debt in an OLG Model with Endogenous Labor Supply," Journal of Macroeconomics 30 (2008), 1323-1328.

Malinvaud, E., The Theory of Unemployment Reconsidered (Oxford: Blackwell, 1977).

Modigliani, F., "Long-Run Implications of Alternative Fiscal Policies and the Burden of the National Debt," Economic Journal 71 (1961), 730-50.

Ogawa, T., "Welfare Analysis of Debt Policy during Recessions," ISER Discussion Paper No. 642 (2005), Osaka University, The Seventh ISER-Moriguchi Prize 2005 Awarded Paper.

Ono, Y., Gokai Darake no Kouzou Kaikaku, in Japanese (Tokyo, Japan: Nihon Keizai Shinbun Sha, 2001).

Persson, T., "Deficits and Intergenerational Welfare in Open Economics," Journal of International Economics 19 (1985), 67-84.

Rankin, N., "Debt Policy under Fixed and Flexible Prices," Oxford Economic Papers 38 (1986), 481-500.

Rankin, N., and B. Roffia, "Maximum Sustainable Government Debt in the Overlapping Generations Model," Manchester School 71 (2003), 217-241.

Romer, D., Advanced Macroeconomics, third ed. (McGraw-Hill: Irwin, 2005).

Saint-Paul, G., "Fiscal Policy in an Endogenous Growth Model," Quarterly Journal of Economics 107 (1992), 1243-1259. 
Sen, P., "Welfare-Improving Debt Policy under Monopolistic Competition," Journal of Economic Dynamics \& Control 27 (2002), 143-156.

Steigum, E., "Trade Unions and the Burden of the Public Debt," CESifo Working Paper Series 587 (2001), CESifo Group Munich.

Tirole, J., "Asset Bubbles and Overlapping Generations," Econometrica 53 (1985), 10711100.

Tobin, J., Asset Accumulation and Economic Activity (Oxford: Basil Blackwell, 1980).

Weil, P., "Overlapping Families of Infinitely-Lived Agents," Journal of Public Economics 38 (1989), 183-98. 